\title{
Mälutööst elulooliste mälu-uuringuteni. \\ Märkusi biograafilise kultuuriuurimise ja nôukogudejärgse Eesti mälu-uuringute seoste kohta
}

\author{
Ene Köresaar \\ Tartu Ülikool, humanitaarteaduste ja kunstide valdkond, \\ kultuuriteaduste instituut, Ülikooli ı6, 51003, Tartu; \\ ene.koresaar@ut.ee
}

Kirsti Jóesalu

Tartu Ülikool, humanitaarteaduste ja kunstide valdkond, kultuuriteaduste instituut, Ülikooli 16, 51003, Tartu, kirsti.joesalu@ut.ee

Kokkuvôte. Artikkel keskendub mälu-uuringute ja eluloouurimise seostele nôukogudejärgsete mäluprotsesside dünaamika ja mälestuste uurimise taustal. Näitame, et eluloouurimise perspektiivist tegid mälu-uuringud läbi muutuse mäluaktivismist mäletamise kontekstide, mäletamisprotsessides tegutsejate, vốimusuhete ja vastuolude kriitilise uurimiseni. Analüüsime asjaomaste institutsioonide panust nôukogudejärgsetesse mälupööretesse. Mälu-uuringute perspektiivist anname ülevaate autobiograafilist mäletamist käsitlevatest uurimustest, keskendudes nii nôukogude perioodi mälestuste uurimise môjukatele teooriatele ja meetoditele kui ka panusele rahvusvahelistesse mäludebattidesse. Osutame olulistele lünkadele eluloolises mälutöös ja selle uurimises, iseäranis eestivenelaste elulugude uurimise väljajätetele ja probleemidele. 
Märksônad: eluloouurimine; suuline ajalugu; mälu-uuringud; nôukogudejärgne pööre; trauma; põlvkond; eestivenelased; nôukogude periood; Teine maailmasôda; mäluajalugu

\section{SISSEJUHATUS}

Artikli eesmärk on analüüsida eluloouurimise ja mälu-uuringute seoseid nõukogudejärgsete mäluprotsesside dünaamika ja mälestuste uurimise taustal. Need uurimissuunad kerkisid esile nóukogudejärgse pöörde käigus, ehkki erineva dünaamika ning erinevate võimalustega toetuda juba olemasolevatele uurimistraditsioonidele. ${ }^{1}$ Mólemad uurimissuunad on olemuselt multidistsiplinaarsed. Omaeluloolise vaatepunkti sees räägitakse „pärimuslikust ajaloost”, „suulisest ajaloost”, „eluloouurimisest” ja „biograafilisest meetodist”, millel on oma metodoloogiline ja uurimislooline ühisosa, aga ka distsipliinidest (folkloristika, ajalooteadus, etnoloogia, kirjandusteadus ja sotsioloogia) tulenevad erinevused. ${ }^{2}$ Lühiduse huvides on artiklis kasutatud terminit „eluloouurimine”, taandamata seda konkreetsele distsipliinile, meetodile vôi allikaliigile. Mälu-uuringud, mida rahvusvaheliselt on kirjeldatud kui "mitteparadigmaatilist, transdistsiplinaarset, keskmeta ettevốtmist”, ${ }^{3}$ on Eestis alates 2000. aastatest kanda kinnitanud nii sotsiaal- ja poliitikateadustes kui ka ajaloo-, kirjandus- ja kultuuriteadustes. Mäluuuringute eripäraseid trajektoore on neis distsipliinides juba hakatud ka lähemalt lahti harutama. ${ }^{4}$ Siinne artikkel pakub lisandust eluloouuringute „aknast” vaadatuna, keskendudes eluloo- ja mälu-uurimise kokkupuutepunktidele ühiskondlikes ja teadusmetodoloogilistes protsessides. ${ }^{5}$ Näitame, et eluloouuringud, mis kogu Ida-Euroopas said kommunistlike režiimide kokkuvarisemise ajal märkimisväärse rolli kaua maha vaikitud mineviku dokumenteerimisel ja avalikustamisel,

I T. Jaago, E. Kôresaar, A. Rahi-Tamm. Oral History and Life Stories as a Research Area in Estonian History, Folkloristics and Ethnology. - Elore, 2006, I3 (I). doi.org/10.30666/ elore.78557; T. Jaago, E. Kôresaar. Pärimusliku ajaloo uurimine Eesti ja naabermaade koostööruumis. - Mäetagused, 2009, 43, 7-I8; M. Tamm. Ajalugu, mälu ja mäluajalugu: uutest suundadest kollektiivse mälu uuringutes. - Ajalooline Ajakiri, 2OI3, I, III-I34; I26-I28.

2 T. Jaago, E. Kốresaar. Pärimusliku ajaloo uurimine Eesti ja naabermaade koostööruumis, 9-II.

3 J. K. Olick, J. Robbins. Social Memory Studies: From “Collective Memory” to the Historical Sociology of Mnemonic Practices. - Annual Review of Sociology, 1998, 24, I, IO5-I40, siin Io6.

4 A. Velmet, L. Kaljundi. Eesti ajalooteaduse uued suunad 21. sajandil. - Acta Historica Tallinnensia, 2020, 26, 167-189, siin 175-178.

5 Siinne ümbertöötatud ja täiendatud diskussioon póhineb ingliskeelsel artiklil, mis keskendus elulugude ja mälestuste kogumise praktikale nôukogudejärgses Eestis: E. Kôresaar, K. Jóesalu. Post-Soviet Memories and 'Memory Shifts' in Estonia. - Oral History, 2016, 47, 47-58. 
on Eestis läbi teinud muutuse mäluaktivismist mäletamise kontekstide, mäletamisprotsessides tegutsejate, vôimusuhete ja vastuolude kriitilise uurimiseni. Selleks analüüsime esiteks asjaomaste institutsioonide panust nôukogudejärgsesse mälupöördesse. Teiseks anname mäluuuringute perspektiivist ülevaate autobiograafilise mäletamise alastest uurimustest, keskendudes nii nôukogude perioodi mälestuste uurimise môjukatele teooriatele ja meetoditele kui ka osutades olulistele panustele rahvusvahelistesse mäludebattidesse. Osutame ka lünkadele eluloolises mälutöös.

\section{ELULOOUURINGUD KUI MÄLUTÖÖ: KOLLEKTIIVSED MÄLESTUSED NÓUKOGUDEJ ÄRGSE PÖÖRDE AJAL JA J $\ddot{A} R E L$}

Suulise ajaloo uurijad Paula Hamilton ja Linda Shopes on asjaolu, et Angloameerika akadeemilises ruumis on mälu-uuringud ja suulise ajaloo uurimine veel hiljuti kulgenud paralleelselt, teineteisega suurt kokku puutumata, põhjendanud nende põhimõtteliselt erinevate uurimisfookuste ja -küsimustega. Nimelt on mälu-uuringud olnud valdavalt keskendunud rahvusriigi tasandi kollektiivsetele praktikatele, ent suulise ajaloo uurimine tegelenud eeskätt sellega, kuidas indiviidid mälestusi loovad ja môtestavad. ${ }^{6}$ Eesti kontekstis muutub see eristus ähmaseks, kuna Nôukogude mineviku môtestamine nôukogudejärgse pöörde ajal ja järel toimus üheaegselt kôikidel ühiskonnatasanditel - individuaalsest juriidilise, komemoratiivse ja institutsionaalseni. Akadeemiline maailm polnud erand. Eestis langes mälu-uuringute algus, mis oli seotud külma sôja lóppemisega ja muutustega akadeemilistes uurimismeetodites, ${ }^{7}$ kokku sotsiaal- ja humanitaarteadustes toimunud biograafilisest pöördest ajendatud eluloouurimise esilekerkimisega. Elulugusid hakati Eestis 1980. aastate lópul ja 1990. aastate algul uurima interdistsiplinaarse algatusena, et koguda ja tôlgendada autobiograafilisi tunnistusi vägivaldsest 20. sajandist. ${ }^{8}$ Uurijad lôid algusest peale sidemeid sel ajal mujal Euroopas

6 P. Hamilton, L. Shopes. Introduction: Building Partnership Between Oral History and Memory Studies. - Oral History and Public Memories. Ed. by P. Hamilton, L. Shopes. Temple University Press, Philadelphia, 20o8, vii-xvii, siinne x.

7 A. Erll. Memory in Culture. Palgrave Macmillian, Basingstoke, 20II, 4-5.

8 T. Jaago, E. Kôresaar, A. Rahi-Tamm. Oral History and Life Stories as a Research Area in Estonian History, Folkloristics and Ethnology. 
ja USA-s hoogu koguvate ja institutsionaliseeruvate mälu-uuringutega. Võib öelda, et Eestis alustati mälu-uurimist eluloolisest perspektiivist. Hiljem lisandusid õiguslik, institutsionaalne ja komemoratiivne perspektiiv. ${ }^{9}$ Eluloouurimise ja mälu-uuringute ühine uurimisfookus oli 2o. sajandi traumaatilistel kogemustel (nagu massiküüditamised ja Teine maailmasôda) ning nende kogemuste pinnalt moodustunud mälukogukondadel ja pôlvkondadel kui aktiivsetel tegutsejatel nôukogudejärgsel mälumaastikul. Nóukogudejärgse pöörde kontekstis seostusid need akadeemilised muutused mälu-uuringutes ja biograafilises pöördes ka ühiskonnas toimuva mälutööga. Eluloouurijate mälu-uuringutele orienteeritud uurimishuvi ja kogumispraktikad olid osa ühiskonnas toimuvatest sümboolsetest tôe- ja mälestamisprotsessidest. ${ }^{10}$ Elulugude kogumine ja uurimine said osaks I980. aastate lópu üldrahvalikust projektist luua individuaalsetest lugudest unikaalne 2o. sajandi „Eesti kogemuse" mälupaik, millega kaasnes antikommunistlik restauratsionistlik „rahvale ajaloo tagasi andmise” ja ,inimesele tema eluloo tagasi andmise” vaim. ${ }^{11}$ Tollases rahvuslikus projektis môisteti üksikisikut rahvuskehandi osana ja indiviidi elulugu rahva ajaloo osana. Suuline ajalugu ja elulookirjutamise suund oli Eesti nõukogudevastases rahvuslikus liikumises aktiivne osaline, vôttes erinevaid metodoloogilisi vorme, et ühiskonnas mälu demokratiseerida. Vôib öelda, et sellisena oli elulugude kogumine Eestis osa Balti riikide iseseisvusliikumisest. ${ }^{12}$

Erinevalt teistest Balti riikidest investeeris taasiseseisvunud Eesti riik vähem sümboolsesse tôe- ja mäletamispoliitikasse. ${ }^{13}$ Kui poliitiliselt jäid retrospektiivse tôe ja ôigluse küsimused küll kauaks oluliseks, ${ }^{14}$ siis sümboolse mälutöö vallas oli suurem roll akadeemilistel organisatsioonidel ja nendega seotud vabaühendustel. Nii said Eestis alates i980. aastate lópust individuaalse mälutöö populaarseks vormiks avalikud üleskutsed elulugude kirjutamiseks. Esimene avalik üleskutse elulugusid kirjutada

9 M. Tamm. Mälupoliitika. - Eesti poliitika ja valitsemine I99I-20II. Koost. R. Vetik. Tallinna Ülikooli Kirjastus, Tallinn, 20I2, I44-I85; E.-C. Pettai, V. Pettai. Transitional and Retrospective Justice in the Baltic States. Cambridge University Press, Cambridge, 2015.

Io E.-C. Pettai, V. Pettai. Transitional and Retrospective Justice, 215-270.

II M. Laar. Veidi meie ajaloolisest mälust - Kultuur ja Elu, 1988, 4, II-I3.

I2 Näiteks Lätis algatati samas vaimus suulise ajaloo projekt, mille eesmärk oli suuliste intervjuude abil koguda elulugusid kui ,ühiskonna kỗige demokraatlikumat mốistmisvahendit” ja seeläbi and inimestele võimalus „täita oma kohustus rahva ees”. Projekti veebilehel on kirjutatud: „Iga inimene ja kóik koos rahvana peavad osalema Läti ajaloo kirjutamisel.” MTÜ Dzīvesstāsts [Elulugu], http://www.dzivesstasts.lv/en/free. php? main=2002 (07.07.2020).

I3 E.-C. Pettai, V. Pettai. Transitional and Retrospective Justice, 255. Näitena vôib tuua inimsusevastaste kuritegude uurimise Eesti rahvusvahelise komisjoni vähese sekkumise ühiskondlikesse debattidesse, vôrreldes Läti ja Leedu sarnaste komisjonidega, ning asjaolu, et Eesti Okupatsioonide Muuseum loodi eramuuseumina.

I4 M. Tamm. Mälupoliitika. 
tehti Tartus asuva Eesti Kirjandusmuuseumi Kultuuriloolise Arhiivi (EKLA) ja sellega seotud MTÜ Ühendus Eesti Elulood (asutati 1996) kaudu i989. aastal. ${ }^{15}$

Avalike üleskutsete taga olevad inimesed olid enamasti humanitaar-ja sotsiaalteaduste erialade teadlased, kuid algselt oli nende eesmärk mõjutada ühiskondlikke protsesse ja rôhk oli elulugude kogumisel, mitte uurimistööl. Ajakirjanduses avaldatud esimeses üleskutses rôhutati elulugude kui kollektiivse mälu kogumise ajaloolist missiooni ja osutati sellele, et „iga elulugu, iga saatus on osa Eesti rahva ajaloost” ${ }^{16}$ I990. aastate teisel poolel tehtud suuremates üleskutsetes („Minu ja mu lähedaste saatus ajaloo keerdkäikudes” I996, „Sajandi sada elulugu” I998) tôsteti tähelepanu keskpunkti Teise maailmasôja ja sellele järgnenud aastatega seotud sündmused. 1996. aasta üleskutses kasutatud saatuse mõiste oli oluline viide sellele, kuidas mõisteti väliste jôudude môju ja otsustavat rolli nii individuaalsele kui ka kollektiivsele tegevusele. 1998. aasta üleskutse järgis suuresti sama tôlgendusliini, keskendudes rahva ajaloo kirjutamisele üksikisikute elulugude avalikustamise kaudu. ${ }^{17}$

Lisaks Eesti Kirjandusmuuseumile ja Ühendusele Eesti Elulood arendas 1990. aastatel oma korrespondentide vôrgu kaudu levitatava avatud küsimustiku meetodi alusel välja eluloo kirjutamise meetodi ka Eesti Rahva Muuseum (ERM). 1990. aastate lópul ühines ERM, sarnaselt EKLA üleskutsetega, suure rahvusliku ajaloo projektiga, kogudes tunnistusi stalinistlikest vangilaagritest ning küüditatute ja sundpõgenike elulugusid. ${ }^{18}$

I5 MTÜ Ühendus Eesti Elulood (https://galerii.kirmus.ee/elulood; 07.07.2020). Avaliku üleskutse meetodit (mida hiljem on nimetatud ka elulookirjutamise kampaaniateks) peeti võimalikult paljude ühiskonnagruppide kaasahaaramiseks kôige sobivamaks. Kirjutamise rôhutamist ei peetud probleemiks: 1980. aastate lópul oli haridustase NSVL-i Euroopa-osas vôrreldav Kanada, USA ja Skandinaavia maadega (vt V. Sirk. Hariduskriis Nóukogude Eestis. - Acta Historica Tallinnensia, 2005, 9, 235-256, siinne 254). Algatajad said toetuda ka Nóukogude Liidule omasele egalitaarsele hobitegevuste süsteemile, mis edendas kõigis ühiskonnagruppides kirjaliku eneseväljenduse oskust. Lisaks sellele polnud kultuuriasutustele kirjutamine Eestis uus praktika. 1920. aastate algusest aitas kaugkogumise meetodite rakendamisele kaasa etnoloogia ja folkloristika erialatraditsioon, mis oli tihedalt seotud elulugude arhiveerimise kogemusega Soomes (vt A. Iuso, J. Horn. Archives. - Encyclopedia of Life Writing: Autobiographical and Biographical Forms. Ed. by M. Jolly. Routledge, New York, London, 20I3, 50). Kuigi algatajad seda üldiselt ei teadvustanud, olid Eesti I980. aastate lópu elulookirjutamise kampaaniad sarnased autobiograafiate vôistlustega 2o. sajandi alguse Poola sotsioloogilises traditsioonis (ibid.) Selle môju kohta saksakeelsele sotsiaalajaloole i97o. aastatel vt: Generationen erzählen: Geschichten aus Wien und Linz 1945 bis 1955. Hrsg. von I. Egger, H. Stockinger. Böhlau, Wien, 2005.

I6 R. Hinrikus. Eesti elulugude kogu ja elulugude uurimise perspektiive. - Vôim ja kultuur. Toim. A. Krikmann, S. Olesk. Eesti Kirjandusmuuseum, Tartu, 2003, I7I-213.

I7 R. Hinrikus. Saateks. - Eesti rahva elulood I. Koost. R. Hinrikus. Tänapäev, Tallinn, 2ooo, $7-\mathrm{I} 2$, siin 8.

I8 1998. aastal avaldas ERM korraga neli küsimuskava Nóukogude massiküüditamiste, vangilaagrite ja sôjajärgse paguluse kohta. Järgnevatel aastate lisandusid küsimuskavad muutustest külma sôja aegse Eesti (ja Välis-Eesti) eri eluvaldkondades. Vt https://www.erm. ee/et/content/kirjasaatjate-vorrk-ja-küsimuslehed (o7.07.2020). 
I990. aastail sai riikliku ajaloopoliitika toel 1940. aastate repressioonide traumanarratiiv domineerivaks minevikust rääkimise viisiks. ${ }^{19}$ Selles arengus oli oluline roll ka akadeemilistel algatustel elulugude kogumise, toimetamise ja avaldamise vallas. Eluloouurija Marianne Liljeströmi ${ }^{20}$ sônul olid sotsialismisjärgses „rahva mälus” domineerivateks kogemusteks repressioonid ja ellujäämine, vangistus ja eksiil, poliitiline dissidentlus ja nii sõjaline kui ka argivastupanu Nôukogude vôimule. Nagu Marta Kurkowska-Budzan Poola suulise ajaloo póhjal väidab, oli ı990. aastatel ajaloo tunnistaja rahvusliku identiteedi ja moraalsete väärtuste kehastaja, kes andis tunnistusi totalitaarse režiimi vôltsi ja moonutatud historiograafia vastu. ${ }^{21}$ Vägivallajärgse mälutöö spetsiifilises kontekstis kaldusid uurijad pidama repressioonimälestusi rutiinse ja rahuliku argielu kajastustest autentsemaks ja seetôttu „tóesemaks”. Lähenemine oli paljuski ka seotud uurijate huviga selle vastu, kuidas indiviidid mótestavad oma kogemusi 2o. sajandi poliitilise ajaloo ja vägivalla kontekstis.

I990. aastate teiseks pooleks Eesti ühiskonna sotsiaalses, õiguslikus ja monumentaalsfääris lóplikult kuju vôtnud nôukogudejärgne mälurežiim ${ }^{22}$ kattis vaid traumaatilise kogemuse (eelkõige stalinlike repressioonide) osa nôukogude perioodi kogemuste spektrist ja kippus summutama vastuolulisi mälestusi. ${ }^{23}$ Välja oli kujunenud nn kannatuse ja vastupanu filter, mille kaudu môtestati tervet nôukogude perioodi erinevatel tasanditel, kuid eelkôige avalikus mälurežiimis. Pärast aastatuhande vahetust hakati tähelepanu pöörama elulugude kogumise ja avaldamise vôimalikele (negatiivsetele) mõjudele elulookirjutajate tegelikule mälutööle. Juba 20oo. aastal avaldas ERM esimese spetsiaalselt hilisnôukogude perioodi (1960.-1980. aastad) kogemusele keskenduva küsimustiku (koostaja Heiki Pärdi). Küsimuskava eessónas väljendati lootust, et möödunud kümne aasta jooksul on inimeste hinnang ajastule muutunud kainemaks ja rahulikumaks. Asjaolu, et EKLA senised 1990. aastate elulookirjutamise kampaaniad vôisid ajendada uusi mäletamise tabusid, tôi esile ka 200o. aastal üleskutsest „Minu ja minu pere elu ENSV-s ja Eesti Vabariigis” tekkinud vastuolu. Üleskutse eesmärk oli keskenduda rohkem nôukogude ja nôukogudejärgse aja argielu kogemustele: igapäevadetailidele, vaimsele óhustikule, lubatule ja keelatule,

I9 M. Tamm. Mälupoliitika.

20 M. Liljeström. Success Stories from the Margins: Soviet Women's Autobiographical Sketches from the Late Soviet Period. - Living Through Soviet Society. Ed. by D. Bertaux, A. Rotkirch, P. Thompson. Routledge, London, 2003, 235-25I.

2I M. Kurkowska-Budzan. Ajaloo tunnistaja ehk Poola suulise ajaloo spetsiifikast. Mäetagused, 20I4, 56, 2I-38, 30 .

22 M. Tamm. Mälupoliitika.

23 E. Kôresaar. A Time Ignored? About the Role of the Soviet Period in Biographies of Older Estonians - Ethnologia Fennica: Finnish Studies in Ethnology, 200I, 29, 45-55. 
ent ka taasiseseisvumisjärgsetele muutustele argielus. ${ }^{24}$ Siiski seletati saadetud elulugudest koostatud raamatu eessõnas nôukogude aja mälestuste kogumise vajadust kannatuse, vôitluse ja ellujäämise metafooride kaudu. ${ }^{25}$ Lisaks sellele osutasid teadlased riskile langeda nóukogude perioodi meenutades „noorusmälestuste nostalgilisse vinesse”, ${ }^{26}$ nähes nostalgias ohtu, millega vôidelda. Reaktsioonina sellele üleskutsele (ja varasematele kampaaniatele) vaidlustasid móned elulookirjutajad idee näha nôukogude aega ainult raskuste kaudu, väljendades soovi vältida 1990. aastatel domineerinud nôukogude perioodi tôlgendamist. ${ }^{27}$ Ühenduse Eesti Elulood kauaaegne esinaine Rutt Hinrikus on selle kokku vôtnud järgmiselt: „Kui Eesti Muinsuskaitse Selts ja teised institutsioonid alustasid mälestuste ja elulugude kogumist, siis jätsid nad sageli mulje, et hinnatakse ainult neid lugusid, mis peegeldavad stalinistlike repressioonide ohvrite kogemusi. Sel pôhjusel vabandavad paljud elulookirjutajad häbelikult, et nad on oma eludest kirjutanud, kuigi midagi märkimisväärset, nagu näiteks Siberisse saatmine, pole nendega juhtunud.”28

Kui ERM jätkas 20oo. aastatel hilissotsialismi perioodi argielu kogemuste talletamist (küsimustikud tööelust, usuelust, toidukultuurist, noortekultuurist, reisikogemustest ja vastavad näitused), siis EKLA lülitus teravnevasse debatti eestlaste rollist Teises maailmasõjas. Eesti ühiskonnas oli see teema esil Venemaa-poolsete pidevate fašismisüüdistuste ja Eesti mälupoliitikat jälgiva Simon Wiesen thali Keskuse avalduste tôttu, mis sattusid vastuollu sõjaveteranide organisatsioonide enesepildiga võitlusest Eesti vabaduse eest. Veteranide endi tegevus tunnustamise nimel saavutas haripunkti Pärnus ja Lihulas asunud „vabadusvõitleja” monumendi ümber puhkenud konfliktis aastatel 2002-2004. ${ }^{29} 2005$. aastal aktualiseerusid Teise maailmasôja mäletamise vastuolud kôrgel välispoliitilisel tasandil, kui tollane Eesti Vabariigi president Arnold Rüütel keeldus osalemast Moskvas Teise maailmasõja lópu puhul korraldatud sõjaväeparaadil. ${ }^{30}$ Juba teema eskaleerumise varases etapis

24 Vt eluloovốistlust kokku vốtva traditsioonilise eluloopäeva kuulutust https://galerii. kirmus.ee/elulood/ajalugu-tegevus/voistlused/ (07.07.2020).

25 M. Lauristin. Inimene ja süsteem. - Eesti rahva elulood III: Elu Eesti NSV-s.

Toim. R. Hinrikus. Tänapäev, Tallinn, 2003, 7-9.

26 M. Lauristin. Inimene ja süsteem, 7.

27 K. Jôesalu, E. Kôresaar. Working Through Mature Socialism: Private and Public in the Estonians' Meaning-making of the Soviet Past. - Baltic Biographies at Historical Crossroad. Ed. by L. Bennich-Björkman, A. Aarelaid-Tart. Routledge, London, New York, 20II, 68-85.

28 R. Hinrikus. Deportation, Siberia, Suffering, Love: The Story of Heli. - She Who Remembers, Survives: Interpreting Estonian Women Post-Soviet Life Stories. Ed. by T. Kirss, E. Kôresaar, M. Lauristin. Tartu University Press, Tartu, 2004, 62-77, siinne 63.

29 K. Brüggemann, A. Kasekamp. Ajaloopoliitika ja „monumentide sôda” Eestis. Monumentaalne konflikt: Mälu, poliitika ja identiteet tänapäeva Eestis. Toim. M. Tamm, P. Petersoo. Varrak, Tallinn, 2008, 70-9I, siin 75-78.

30 E.-C. Onken. The Baltic States and Moscow's 9 May Commemoration: Analysing Memory Politics in Europe. - Europe-Asia Studies, 2007, 59, I, 23-46. 
kuulutas EKLA välja üleskutse „Minu elu Saksa ajal” (2003), mille vastusena laekus i9o elulugu. Aasta hiljem, Teise maailmasõja lópu aastapäeva eelôhtul, organiseeriti eluloovõistlus „Sõja mõjud minu ja meie pere elus” (2004-2005), mis osutus sama populaarseks. Mólemad üleskutsed erinesid märkimisväärselt eelmise kümnendi omadest, sest ei püüdnud kampaaniaid ideoloogiliselt raamistada. „Minu elu Saksa ajal” eristus oma detailsusega, sarnanedes enam avatud küsitluse meetodi kui üleskutsega; ${ }^{31}$ „Sõja mõjud” omakorda vôrdles pigem Teist maailmasôda varasemate või hilisemate sõjakogemustega (nt Praha kevad 1968 või Nôukogude-Afganistani sõda 1979-1989) ega keskendunud niivôrd selle ainulaadsele tähendusele Eesti ajaloos. ${ }^{32}$ Kuigi üleskutsete organiseerijad eeldasid, et avalik konflikt Teise maailmasõja kogemuste teemal kajastub ka elulugudes, ei ilmnenud see sellisel määral kui nôukogude perioodi mälestustes. ${ }^{33}$

20oo. aastate lópust on EKLA pidanud tunnistama elulookirjutamise üleskutse meetodi populaarsuse vähenemist ühiskonnas. Ühest küljest vôib selle pôhjuseks olla asjaolu, et elulugude ja mälestuste kogumine ja avaldamine oli muutunud üha laialdasemaks kohalike grupispetsiifiliste algatuste kaudu: isiklikke mälestusi kirjutasid ja avaldasid koolide vilistlased, väliseestlased vôi võórsil sündinud, küüditatute lapsed jpt. See tingis rahvaliku elulookirjutuse mitmekesistumise ja killustumise. Teisest küljest leidsid üleskutsed, mis puudutasid eluloo ja ajaloo puutepunkte, vähem vastukaja.

Senini pole sotsiaalsete teemade tôstatamine olnud EKLA tugev külg. 1990. aastail tehti Póhjamaade uurijate ja ametiühingute algatusel môned katsed koguda lugusid seksuaalsusest (1995) ja ôpetajaks olemisest (1998). 20I2. aastal, kui ópetajad oma palganôude toetuseks streikisid, püüdis EKLA samuti innustada ópetajaid mälestusi kirjutama, kuid väga vähese eduga. ${ }^{34}$

Praegu integreeritakse Eesti Kirjandusmuuseumi katuse all EKLA kogumistööd üha enam Eesti Rahvaluule Arhiivi tegevusega. Saame näha, kuidas see hakkab môjutama elulugude kogumise tööd ja

3I Muuseum ootab mälestusi kirja panema. Trükis avaldatud versioon üleskutsest „Minu elu Saksa ajal": https://galerii.kirmus.ee/elulood/ajalugu-tegevus/voistlused/ (07.07.2020).

32 R. Hinrikus. Algas eluloovôistlus „Sõja mõjud minu ja meie pere elus”. - Vooremaa, 2004, 5. november. https://www.vooremaa.ee/kirialgas-eluloovoistlus-soja-mojud-minu-ja-meiepere-elus/ (07.07.2020).

33 E. Kóresaar. Introduction: Remembrance Cultures of World War II and the Politics of Recognition in Post-Soviet Estonia: Biographical Perspectives. - Soldiers of Memory: World War II and its Aftermath in Estonian post Soviet Life Stories. Ed. by E. Kôresaar. Rodopi, New York, Amsterdam, 20II, I-34, siinne 8.

34 Mina, ópetaja: Valik eesti ópetajate mälestusi elust ja koolist aastatel 1940-20ıo. Koost. R. Hinrikus. Hea Lugu, Tallinn, 20I5. 
mälu-uuringuid. Eluloolisi mälu-uuringuid, mis Eestis pöörde ajal esile kerkisid, mõjutasid tugevalt traumaatilise mineviku mälestused ning need olid haaratud tõe otsimise ja mälestamise protsessi mitte ainult akadeemiliselt, vaid ka mäluaktivismi vormis. Viimase kahekümne aasta jooksul on elulookirjutamise üleskutsed jäänud suuresti seotuks oma algse eesmärgiga „kirjutada indiviid tagasi rahvuse lukku”, ${ }^{35}$ samal ajal kui akadeemilised mälu-uuringud on eristunud elulugude kogumise praktikast kriitilisema ja refleksiivsema lähenemisega mälule.

\section{MÄLU-UURINGUD JA NÕUKOGUDEJ ÄRGSED ELULOOD: TEEMAD, METODOLOOGIAD}

\section{JA KRIITIKA}

Eesti eluloolised mälu-uuringud, keskendudes teemadele, mis poliitilistel ja ajaloolistel pôhjustel olid kôikjal Euroopas kommunismijärgsete uuringute keskpunktis, ${ }^{36}$ said esmalt inspiratsiooni Saksa Zeitgeschichte'st (lähiajalugu) ja Erzählforschung'ist (jutu-uurimine). ${ }^{37}$ Saksa kultuurimälu uurimissuund (eelkôige kommunikatiivse ja kultuurimälu mõiste $)^{38}$ inspireeris küsimusi indiviidist ja kollektiivist eluloonarratiivis ning Angloameerika sotsiaalse mälu uurimissuund ${ }^{39}$ uurimistööd ajaloo, mälu ja identiteedi, samuti võimu ja vastuolude alal, eriti mis puudutas eluloolise mäletamise ja rahvusliku mälupoliitika suhet. Alates 2oro. aastatest on sisupoohist vaatenurka narratiivsele mälule täiendanud performatiivsed ja protsessuaalsed lähenemised, mis keskenduvad mäletamise dünaamikale, vahendamisele ja vôrgustumisele. ${ }^{40}$

35 Üks viimaseid suuremaid Ühenduse Eesti Elulood kampaaniaid oli pühendatud Eesti iseseisvuse roo. aastapäevale ja rôhutas taas inimese ja riigi suhet, vt https://galerii.kirmus. ee/elulood/ajalugu-tegevus/voistlused/ (07.07.2020). Selle tulemusena ilmus kaheköiteline kogumik „Minu elu ja armastus” (Eesti rahva elulood, I.-2. kd. Koost. ja toim. R. Hinrikus, T. Kirss. Tänapäev, Tallinn, 2018).

36 Reclaiming the Personal: Oral History in the Post-Socialist Europe. Ed. by N. KhanenkoFriesen, G. Grinchenko. University of Toronto Press, Toronto, 2015.

37 A. Lehmann. Erzählstruktur und Lebenslauf: Autobiographische Untersuchungen. Campus, Frankfurt am Main, New York, 1988.

38 Eelkốige toetuti siinjuures Aleida ja Jan Assmanni varastele töödele: J. Assmann. Kollektiivne mälu ja kultuuriline identiteet. - Akadeemia, 20I2, 24, IO, I775-I786, originaalartikkel ilmus kogumikus: Kultur und Gedächtnis. Hrsg. von J. Assmann, T. Hölscher. Suhrkamp, Frankfurt am Main, 1988, 9-19; A. Assmann. Erinnerungsräume: Formen und Wandlungen des kulturellen Gedächtnisses. C. H. Beck, München, 1999

39 Vt ülevaadet: The Collective Memory Reader. Ed. by J. K. Olick, V. Vinitzky-Seroussi, D. Levy. Oxford University Press, Oxford, 2011.

40 Vt lähemalt: A. Erll. Kollektives Gedächtnis und Erinnerungskulturen. J. B. Metzler, Stuttgart, 2005; A. Erll. Literature, Film, and the Mediality of Cultural Memory. - Cultural Memory Studies: An International and Interdisciplinary Handbook. Ed. by A. Erll, 
Akadeemilised mälukontseptsioonid eluloonarratiivide uurimiseks on kujunenud paralleelselt kogumistööga alates i990. aastate teisest poolest. Keskseks uurimisteemaks, mis tôstatas kriitiliselt kultuuriliste ja poliitiliste tabude kujundamise küsimuse, oli nôukogude perioodi mäletamise teema. Sajandivahetuseks oli nôukogudejärgse pöörde tulemusel välja kujunenud nôukogude perioodi kannatuse ja vastupanu vôtmes käsitlemise hegemooniline diskursus, mida esindas uurimustes katkestuse metafoor. ${ }^{41}$ Üldjoontes tähistas katkestuse metafoor viisi, kuidas môtestati Eesti avalikkuses Nóukogude minevikku, elulookirjutusest seadusandluseni, st kui ajalooperioodi, mis katkestas Eesti riikliku iseseisvuse ja „eestipärase elu”. Katkestuse diskursus kujunes I990. aastatel avaliku tôeotsimise ja mälestamisprotsessi tulemusel ja - nagu ülal osutatud elulookirjutamise üleskutsete märkimisväärsel toel. Tuginedes 1990. aastate lópuks kogunenud suurele hulgale olemasolevatele eluloolistele allikatele, ${ }^{42}$ algatas Tartu Ülikooli etnoloogia osakond 1998. aastal esimese mälu-uuringute projekti, mis esitas küsimuse poliitilise ja kultuurimälu toimimisest eluloonarratiivides. ${ }^{43}$ Uurimisküsimuste kaudu püüti môista mineviku tôlgendamise kultuurilist loogikat Eesti elulugudes nôukogudejärgse pöörde ajal ja järel. Küsimusi, millised „mälupildid” ${ }_{44}$ tekivad ning miks ja mida nad nôukogudejärgse identiteedi ja mälukultuuri seisukohalt tähendavad, käsitleti juhtumiuuringutes, mis analüüsisid stalinismi, Teise maailmasõja ja sõjaeelse ühiskonna autobiograafilisi representatsioone. ${ }^{45}$ Mälestust stalinismist kontseptualiseeriti „mälufiltrina”, mille kaudu anti postkommunistlikus mälukultuuris tähendusi teistele 20 . sajandi perioodidele. ${ }^{46}$

A. Nünning. Walter de Gruyter, Berlin, New York, 2008, 389-398; A. Rigney. The Dynamics of Remembrance: Texts Between Monumentality and Morphing. - Cultural Memory Studies, 345-353.

4I E. Kôresaar. Elu ideoloogiad: Kollektiivne mälu ja autobiograafiline minevikutôlgendus eestlaste elulugudes. Eesti Rahva Muuseum, Tartu, 2005.

42 Lisaks Eesti Rahva Muuseumi arhiivile oli 1990. aastate lópuks ka Eesti Kultuuriloolises Arhiivis üle tuhande Ühenduse Eesti Elulood poolt kogutud eluloo.

43 E. Vunder, T. Anepaio, E. Kôresaar. Research Project: Memory as a Cultural Factor in the Biographical Narratives of the Estonians - Pro Ethnologia, 1998, 6, 89. ETF projekt „Mälu kui kultuuritegur eestlaste biograafilistes narratiivides” (I998-200I, Tartu Ülikool, ERM).

44 F. Heins. Über Geschichtsbilder in Erinnerungserzählungen. - Zeitschrift für Volkskunde, 1993, 89, 63-77.

45 Vt vastavalt: K. Siemer. Võim, indiviid ja kohanemine elulugudes: Vanemad eestlased elust Nõukogude Eestis. - Mälu kui kultuuritegur: Etnoloogilisi perspektiive. Toim. E. Kõresaar, T. Anepaio. Tartu Ülikooli Kirjastus, Tartu, 2003, I24-I49; T. Mulla. Minu ónnelik-rahutu lapsepôlv: 1940. aastad eestlaste lapsepôlvemälestustes. - Mälu kui kultuuritegur, 92-I23; R. Ruusmann. The Establishment of Collective Farms and Their Early Years as an Image of History in the Estonians' Life Stories. - Pro Ethnologia, 2003, 16, 2I-37.

46 E. Kõresaar. The Notion of Rupture in Estonian Narrative Memory: On the Construction of Meaning in Autobiographical Texts on the Stalinist Experience. - Ab Imperio, 2004, 4, 313-339; E. Korresaar. The Culture of Remembrance of the Second World War in Estonia as Presented in Post-Soviet Life Stories: On the Logic of Comparison Between the Soviet and the Nazi Occupations. - We Have Something in Common: The Baltic Memory. Ed. by A. Mihkelev, B. Kalnačs. Under and Tuglas Literature Centre of the Estonian Academy of Sciences, Tallinn, 2007, 35-60. 
Aastatuhande vahetuseks kujunes algne lähtumine Assmannide kommunikatiivsest ja kultuurimälu mudelist epistemoloogiliseks väljakutseks eluloouurijatele, kes analüüsisid katkestuse diskursuse seost stalinismikogemusega nôukogudejärgses autobiograafilises minevikumõtestamises. Metodoloogilist inspiratsiooni pakkunud Jan Assmanni varases kultuurimälu teoorias póhineb kommunikatiivse ja kultuurimälu eristamine peamiselt erinevate mäluvormide institutsionaliseerumise ja kinnistumise tasemel, samuti ajalisusel. ${ }^{47}$ See teooria selgitas kommunikatiivse mälu transformeerumist kultuurimäluks, kuid ei pööranud tähelepanu kultuurimälu môjule ja rollile kommunikatiivses mäletamises. ${ }^{48}$ Ühiskonnas toimuva aktiivse mälutöö kontekstis, kus arvukad narratiivsed ressursid pidevalt aktiveerusid, ringlesid, rakendusid ja muutusid, oli eluloouurimise seisukohalt väga oluline kommunikatiivse ja kultuurimälu vahelisi seoseid eluloojutustamises teoretiseerida.

Uurimaks dünaamilisi suhteid omaeluloolise mäletamise kogemustasandi ja normatiivsete tôlgenduste vahel ning seoseid spetsiifilise ajaloolise ja sotsiaalse kontekstiga, lähtuti ı990. aastate lópu ja 200o. aastate alguse etnoloogilises eluloouurimises esialgu kultuurimälu uuringutes vähe tähelepanu pälvinud Peter Alheiti sotsiaalse mälu mudelist. ${ }^{49}$ Alheitist inspireerituna vôttis Ene Kôresaar kasutusele biograafilise sünkretismi môiste, et esile tôsta mäletamise ja loo jutustamise dialoogilisi mehhanisme: mälu-uuringute perspektiivist võib elulugusid mõista kui tôlgenduste sünkretistlikke esitusi, mis vôrsuvad eri aegadest ja erinevatest fenomenoloogilistest reaaliatest. ${ }^{50}$

47 J. Assmann. Kollektiivne mälu ja kultuuriline identiteet.

48 Vt kriitikat: E. Kóresaar. Memory and History in Estonian Post-Soviet Life Stories: Private and Public, Individual and Collective from the Perspective of Biographical Syncretism. University of Tartu Press, Tartu, 2004, 38-4I. Hiljem on ka Aleida Assmann soovitanud eristada kultuurimälu vorme. Kultuurimälu vôib olla „aktiivne” (Funktionsgedächtnis, kaanon) või „passiivne” (Speichergedächtnis, arhiiv) (vt A. Assmann. Erinnerungsräume; aga ka A. Assmann. Zur Mediengeschichte des kulturellen Gedächtnisses. - Medien des kollektiven Gedächtnisses. Konstruktivität - Historizität - Kulturspezifität. Hrsg. von A. Erll, A. Nünning. Walter de Gruyter, Berlin, New York, 45-6o, siinne 47 jj; A. Assmann. Der lange Schatten der Vergangenheit: Erinnerungskultur und Geschichtspolitik. C. H. Beck, München, 2006, 54 jj). Oma hilisemates kirjutistes on Aleida Assmann laiendanud oma diakrooniliselt opositsioonilist vaadet kommunikatiivse ja kultuurimälu suhtele (nt A. Assmann. Canon and Archive. - Cultural Memory Studies, 97-IO7). Hiljutiste rahvusvaheliste debattide kohta Assmanni kultuurimälu teooria teemal vt: K. Jóesalu. Dynamics and Tensions of Remembrance in Post-Soviet Estonia: Late Socialism in the Making. (Dissertationes Ethnologiae Universitatis Tartuensis, 6.) University of Tartu Press, Tartu, 2017, 26-29.

49 P. Alheit. Erzählform und Asoziales Gedächtnis: Beispiel beginnender Traditionsbildung im autobiographischen Erinnerungsprozess. - Biographisches Wissen: Beiträge zu einer Theorie lebensgeschichtlicher Erfahrung. Hrsg. von P. Alheit, E. M. Hoerning. Campus, Fankfurt am Main, 1989, I23-I47; E. Kôresaar. Mälu, aeg, kogemus ja eluloouurija pilk. Mälu kui kultuuritegur, 7-32.

so E. Kôresaar. Memory and History, 53. 
Seda môttesuunda järgides uuriti ka neid elulugude narratiivseid skeeme, mis andsid tunnistust „süvamälust” - narratiivsete traditsioonide tôlgendusvôrgustikust, mis organiseerib sündmuste mäletamist ja võimaldab mäletatavaid sündmusi ajas, ruumis ja sotsiaalsetes kontekstides seostada. James Wertsch käsitles mäletamist kui „tekstuaalsete ressursside” "vahendatud tegevust”. ${ }^{51}$ Vahendamist ja taasvahendamist käsitlevad kultuurimälu uuringud Astrid Erllilt ja Ann Rigneyilt ${ }^{52}$ inspireerisid uuringuid eluloo ja kultuurimälu kanooniliste tekstide kui mälumeediumide vastastiktoimest 1990. aastate mälutöös, mis kujundas arusaamu 2o. sajandi minevikust ja lôi ühiskonnas tulevaste mäletamisaktide tegevusraamistiku. ${ }^{53}$ Nagu näitame ka edaspidi, on samade autorite vahendamist ja mäluvormide rändamist vaatlevad tekstid môjutanud ja toetanud analüüse trauma ja erinevate kultuuriüleste mäluvormide ilmnemisest Eesti eluloolises mäletamises ja kultuuritekstides. ${ }^{54}$

I980. aastate lópul ja I990. aastatel polnud traumaatilisest kogemusest erinevad nõukogude aja kogemused veel avalikkuses „hääleõiguslikud”. Oma kaastöödega kirjutasid inimesed ennast Eesti ajalukku ja Eesti ajalugu omakorda löödi lahku Nôukogude Liidu ajaloost. 2I. sajandil tuli käibele uus paradigma, mis tôi esile nôukogude kogemuse mitmekihilisuse. Nóukogude argielu analüüsid, mis keskendusid tööelu, sotsiaalsete suhete ja defitsiidivôrgustike teemadele, juhtisid tähelepanu uutele tabudele, mis tekkisid nôukogudejärgse pöörde käigus. Näiteks osutus keerukaks uurida inimeste kogemusi varimajandusest, sest muutunud tööeetika kontekstis kartsid jutustajad, et need kogemused pole kooskôlas kaasaegsete normidega. Sójajärgsete kolhooside argielu uurijad problematiseerisid nõukogudejärgset avalikku hoiakut nóukogude põllumajandusettevõtete suhtes, näidates sõjaeelse elustiili jätkumist 1960. aastateni. Argielu etnoloogiliste uuringute panus mälu-uuringutesse seisnes selles, et need osutasid, mil määral nôukogudejärgne mälukultuur häbimärgistas „normaalsuse” kogemust nôukogude perioodil. ${ }^{55}$

5I J. Wertsch. Voices of Collective Remembering. Cambridge University Press, Cambridge, 2002.

52 A. Erll, A. Rigney. Introduction: Cultural Memory and its Dynamics. - Mediation, Remediation, and the Dynamics of Cultural Memory. Ed. by A. Erll, A. Rigney. Walter de Gruyter, Berlin, New York, 2009, I-II, siinne Io.

53 E. Kôresaar. Life Story as Cultural Memory: On the Role of the Textual Community in Post-1989 Memory Work. - Cultural Patterns and Life Stories. Ed. by K. Jóesalu, A. Kannike. Tallinn University Press, Tallinn, 2016, 104-129.

54 Vt nt E. Laanes. Trauma keelde tôlgitud: Kultuurideülesed mäluvormid eesti küüditamisja laagrimälestustes. - Keel ja Kirjandus, 2017, 4, 24I-257.

55 Vt K. Jõesalu. "The Right to Happiness": Echoes of Soviet Ideology in Biographical Narratives'. - Berliner Osteuropa Info, 2005, 23, 9I-99. Vt nt I. Jääts. Töö kolhoosis: Oisu piirkond Järvamaal 1940. aastate lópust 1960. aastate lópuni. - Eesti Rahva Muuseumi aastaraamat. Eesti Rahva Muuseum, Tartu, 2002, 27-50. 
Üks esimesi kogutud elulugude interdistsiplinaarse analüüsi katseid oli 2004. aastal avaldatud kogumik „She Who Remembers Survives" ${ }^{56}$ See tôi kokku Eestis elulugude uurimise ja mälu-uuringutega tegelevad inimesed. Kogumikus ei vaadeldud nôukogude kogemust ainult läbi repressioonide prisma, vaid osutati elulugude valiku kaudu ka kogemustele, mis olid eelmisel kümnendil tabuks muutunud: näiteks naise lugu, kes oli abielus kommunistiga ja pärast sôda Nóukogude sôduriga ning kes oli saadetud natslikku koonduslaagrisse, samuti lugu Venemaal sündinud naistraktoristist, Nóukogude Liidu töökangelasest. ${ }^{57}$ See kogumik, nagu ka paar aastat varem avaldatud naiste elulugude antoloogia „Naised räägivad”, ${ }^{58}$ aitas kaasa naiste kogemuse nähtavuse kasvule nóukogudejärgses ühiskonnas. Kohanemist, vastupanu ja ambivalentsust naiste lugudes analüüsiti mineviku ja kujunevate ajalooliste tôerežiimide kontekstis. 2006. aastal ilmunud „Carrying Linda’s Stones” püüdis omakorda esitada naiste lugusid 20. sajandi sooideoloogiate, eriti nôukogude soohierarhiate raamistikus. ${ }^{59}$

Naiste elulugude, eelkõige represseeritud ja küüditatud naiste lugude uurimise märkimisväärseks tulemuseks on traumateooria kriitika Eesti eluloouurimises.$^{60}$ Nüüdisaegses mälu-uurimises haarab trauma mõiste vägivaldseid (ajaloo)sündmusi kogu maailmas, kaardistades poliitiliste konfliktide ja ülekohtu kogemust. Eesti eluloouurimise kontekstis on Hinrikus traumalugudena määratlenud 1940. aastate massivägivallale keskenduvaid lugusid, mis kattub ka määratlusega n-ö ühiskondlikus mälus. ${ }^{61}$ Tiina Kirss on hoiatanud traumateooria ülihôlmava kasutuse eest ning osutanud, et individuaalsete jutustuste heterogeensust on kerge ignoreerida, kui teooriakasutus vôi ühiskondlik mälu „,,traumatiseerib” need kanooniliseks kannatuslooks" ${ }^{62}$ Kirjandusteadlased Tiina Kirss ja Leena Kurvet-Käosaar on naiste repressioonilugusid analüüsides näidanud, et Eesti nôukogudejärgses elulookirjutuses ei ole domineerinud traumadiskursus ning traumateooria kasutamine vajab kriitilisi korrektiive, kuna eluloojutustajad võtavad tavaliselt aktiivse tegija, mitte

56 T. Kirss, E. Kõresaar, M. Lauristin. She Who Remembers Survives.

57 Kuigi kogumik peegeldab nôukogude naise kogemust mitmekesise ja vastuolulisena, siis tôlgendati neid elulugusid peamiselt siiski rahvusliku narratiivi raamistikus.

58 Naised kốnelevad. Toim. E. Annuk. Eesti Kirjandusmuuseum, Tartu, 1997.

59 Carrying Linda's Stones: An Anthology of Estonian Women's Life Stories. Ed. by S. S. Lie, L. Malik, I. Jõe-Cannon, R. Hinrikus. Tallinn University Press, Tallinn, 2006.

6o Traumadiskursuse kujunemise kohta Eesti mäluruumis vt: E. Laanes. Trauma keelde tôlgitud; multidistsiplinaarsete traumauuringute kohta vt: T. Jaago. Trauma ja elulood. Mäetagused, 20I8, 7I, III-I42.

6I R. Hinrikus. Eesti elulugude kogu.

62 T. Kirss. Pógenemisteekonnad ja pógenemislood. - Rändlindude pesad: Eestlaste elulood vôõrsil. Eesti Kirjandusmuuseum, Tartu, 2006, 6II-646, siin 6I7. 
passiivse ohvri positsiooni. ${ }^{63}$ Diskussioon traumateooria rakendamisest küüditamisnarratiividele paigutub rahvusvaheliselt selliste uurimuste konteksti, mis püüavad traumateooriat dekoloniseerida ja „läänelikke” sündmuspôhiseid traumamudeleid ümber kujundada. ${ }^{64}$ Teisalt lähtub traumateooria kriitika selle üha valdkondadevahelisemast kontekstist. Folklorist Tiiu Jaago on rôhutanud, et „,[k] ui traumateooria vôimaldab analüüsida ühiskonnas aktuaalseid ja kultuuriüleseid traumailminguid ning esitusviise, siis elulugudes tulevad esile trauma individuaalsed, lokaalsed ja kultuurisidusad aspektid"; 65 trauma eluloos ei pruugi olla üksnes sündmuspôhine, vaid on dünaamiline, mitmesuunaline ja -tasandiline ning dialoogiline. ${ }^{66}$

Lisaks traumateooriale leidis 200o. aastate eluloouurimises kultuuritrauma kontseptsioon kasutust ka ootamatu õigustest ilmajätmise, sotsiaalse ja kultuurilise marginaliseerimise mõistes, kui uuriti eestlaste nôukogudeaegset mentaliteeti ja I990. aastatel kujunenud eestivenelaste hoiakuid. ${ }^{67}$ Kuigi 1940. aastate traumaatilised kogemused polnud Eesti eluloolistes mälu-uuringutes 2oro. aastateks enam nii esiplaanil kui varem, säilitasid need oma olulise koha uute uurimisprobleemide valgusel, näiteks migratsiooniuuringutes. ${ }^{68}$ Migratsiooniuuringute hulka kuuluvad ka móned Eesti vähemusgruppide kohanemist ja identiteeti käsitlevad varasemad tööd. ${ }^{69}$

Kirsi uurimused Eesti pagulaste lugudest osutasid keerukatele seostele nii 1940. aastate kannatusnarratiivis kui ka migratsiooniloos. Tema käsitlus nende eestlaste elulugudest, kes pääsesid I944. aastal Läände, tôstatas küsimusi pagulaste (ja eriti paadipógenike) sildistamisest nii külma sõja aegses Läänes kui ka nõukogudeaegses ja -järgses Eestis. I940. aastail emigreerunud inimeste mälukultuuri (pagulaste „rajavaid jutustusi”) analüüsis Kirss selle mäluajaloolises kujunemises ja dialoogis teiste

63 T. Kirss. Three Generations of Estonian Women: Selves, Lives, Texts. - She Who Remembers Survives, II2-I43:I24, T. Kirss. Survivorship and the Eastern Exile: Estonian Women's Life Narratives of the 1941 and 1949 Siberian deportations. - Journal of Baltic Studies, 2005, 36, I, 13-38; L. Kurvet-Käosaar. Voicing Trauma in the Deportation Narratives of Baltic Women. - Haunted Narratives: Life Writing in an Age of Trauma. Ed. by G. Rippl, P. Schweighauser, T. Kirss, M. Sutrop, T. Steffen. University of Toronto Press, Toronto, Buffalo, London, 2013, I29-I5I.

64 S. Craps. Postcolonial Witnessing: Trauma Out of Bounds. Palgrave Macmillan, Basingstoke, 20I2; D. Budryte. Decolonization of Trauma and Memory Politics: Insights from Eastern Europe. - Humanities, 2016, 5, 7. https://doi.org/10.3390/h5010007.

65 T. Jaago. Trauma ja elulood, III.

66 Samas, I34-I35.

67 A. Aarelaid-Tart. Cultural Trauma and Life Stories. Kikimora, Helsinki, 2006.

68 A. Rahi-Tamm. Eesti kodanike sundmigratsioon itta 194I-5I: Môningaid vôrdlusjooni Läände pógenenute loole. - Acta Historica Tallinnensia, 20II, 17, 72-94.

69 R. Reinvelt. Ingeri elud ja lood: Kultuurianalüütiline eluloouurimus. Tartu Ülikooli Kirjastus, Tartu, 2002. 
geograafiliselt, poliitiliselt ja kultuuriliselt eraldatud mälukultuuridega, mis olid samuti surutud spetsiifilisse emigrantlikku keskkonda. ${ }^{70}$

Ühtlasi esitati elulugusid analüüsides küsimus, kuidas nôukogudejärgse pöörde ajal kujunenud nôukogude kogemuse mõistmine mõjutas autobiograafilist loojutustamist. Selles valdkonnas viidati näiteks ühtse läbiva narratiivi puudumisele hilisnôukogude perioodi kogemuste kirjeldustes ja tendentsile jätta kogu selle perioodi argielukogemus elulooülevaadetest välja. ${ }^{71}$ Veel üks interdistsiplinaarne elulooliste mälu-uuringute valdkonna uurimisprojekt „Mälupraktikad: järjepidevused ja katkestused 2o. sajandi mäletamises" (20IO-20I4, TÜ) lähtus hüpoteesist, et katkestust (vt eespool katkestuse diskursus) ja järjepidevust tuleb mõista mitte üksteisele järgnevatena, vaid samaaegselt, üksteise kaudu toimivatena, kusjuures nad aktualiseeruvad kindlates olukordades. Sellele hüpoteesile tuginedes tôstatas Jaago kultuurilise järjepidevuse teema omaeluloolistes jutustustes: ta rôhutas katkestuse ja järjepidevuse vältimatut vastastikseost, tuues esile, et elulood kujutavad argielu ja kirjutaja enesepilti järjepidevuse vôtmes, vaatamata poliitilises elus toimunud katkestustele (nt poliitilised arreteerimised). ${ }^{72}$ Et juhtida tähelepanu katkestuse metafoori mälupoliitilisele iseloomule, rakendati kriitilise nostalgia môistet, et viidata nôukogude kogemuse vahendamisel võimusuhetele. ${ }^{73}$

Nagu eespool märgitud, muutus nôukogude kogemuse kogumine ja vahendamine Eesti ühiskonnas 200o. aastate alguses taas aktuaalseks. Selles kontekstis problematiseerisid uurijad üha enam ka hilisnôukogude perioodi mäletamisväärtust. Esmalt esitas Kirsti Jõesalu, rakendades mälupaiga mõistet (Pierre Nora), küsimuse raamistiku kohta, milles hilisnôukogude perioodi saab mälupaigana analüüsida: kui avalike tekstide analüüs näitas, et poliitilisel tasandil oli „nôukogude aeg” muutunud suhteliselt kinnistunud mälupaigaks ${ }^{74}$ siis teistele mäletamise tasanditele (nt film, näitus, kirjandusteos, elulood ja mälestused) liikudes tuleb rakendada dünaamilisemat lähenemist. ${ }^{75}$ Uurides jätkuvaid mäletamisprotsesse suhteliselt kompaktsel mälumaastikul nagu Eesti, kus

$70 \quad$ T. Kirss. Rändlindude pesakonnad.

7I K. Jóesalu. "We Were Children of Romantic Era": Nostalgia and the Non-Ideological Everyday Through a Perspective of Silent Generation. - Journal of Baltic Studies, 2016, 47, 4, 557-577; E. Kốresaar. A Time Ignored?

72 T. Jaago. Discontinuity and Continuity in Representations of 2oth Century Estonian History. - Culture Unbound: Journal of Current Cultural Research, 2014, 6, I07I-I094.

73 E. Kôresaar. Nostalgia ja selle puudumine eestlaste mälukultuuris: eluloouurija vaatepunkt. - Keel ja Kirjandus, 2008, 10, 760-771; K. Jóesalu. "We Were Children of Romantic Era”.

74 K. Jóesalu. The Role of the Soviet Past in Post-Soviet Memory Politics through Examples of Speeches from Estonian Presidents. - Europe Asia Studies, 20I2, 64, 6, IOO7-IO32.

75 K. Jôesalu. The Meaning of "Late Socialism”. Analyzing Estonians' Post-Communist Memory Culture. - Asia Europe Journal, 2010, 8, 3, 293-303. 
mäletamise eri dimensioonid pidevalt ristuvad, tuleb arusaama (kollektiivsest) mälust revideerida. Analüüsides uuemaid tekste hilissotsialismist, vaadati uuesti üle Assmannide pakutud teoreetiline raamistik, eeskätt seoses diakroonilise opositsiooniga kommunikatiivse ja kultuurimälu vahel. ${ }^{76}$ Analüüsides hilissotsialismi mälu loomise protsessi, väitsid Jóesalu ja Raili Nugin, et suhteliselt hiljuti loodud ja lähiminevikku puudutavaid tekste - mida ka edastati kommunikatiivse mälu väljal - tuleks samuti mõista kultuurimälu osana. ${ }^{77}$ Tegeledes sellise lähiminevikuga nagu hilissotsialismi aeg, pole kommunikatiivse ja kultuurimälu range eristamine vajalik. Erinevate mäluvormide vahelised piirid on hägusad, näiteks toetub mäluloomes môjukas kultuurilooming autorite põlvkondlikele ja individuaalsetele lugudele, eri pôlvkonnakohordid kasutavad eri kanaleid oma minevikuversioonide väljendamiseks ja vahendamiseks ning panustavad mäludünaamikasse ühtaegu kultuuri-, poliit- ja sotsiaalsfääris. ${ }^{78}$ Seega, nagu uurimused hilissotsialismi tôlgendamisest Eestis on näidanud, on tegelikus mälutöös kultuuriline ja kommunikatiivne omavahel seotud, põimunud ja toetuvad pidevalt teineteisele.

Assmanni kultuurimälu teooria kriitika - nii see, mis pärineb 200o. aastate algusest, ${ }^{79} \mathrm{kui}$ ka see, mis pärineb 20ıo. aastatest ${ }^{80}$ - on sõnastatud eri lähtekohtadelt ja märgistab Eesti elulooliste mälu-uuringute dünaamikat. 200o. aastate kriitika lähtus huvist eluloonarratiivi/ teksti kui mäletamisprotsessi „produkti” vastu ning küsis, kuidas omaeluloolises tekstis toimub erinevate mäletamisvormide vaheline vastastikmõju: kuidas väljendub individuaalne kollektiivses ja kollektiivne individuaalses. 1990. ja 2000. aastate mälu-uuringutele olid tunnuslikud objektikeskne vaade ja küsimuseasetused, mis murdsid pead individuaalse ja kollektiivse mälu epistemoloogiliste lahknevuste üle. ${ }^{81}$ 20Io. aastate kriitika aga paigutus sel ajal kultuuriuuringutes üldiselt toimuvasse nihkesse „väljunditelt protsessidele” ehk Ann Rigney sônul „kultuurilistele artefaktidele keskendumiselt huvile selle vastu, kuidas need artefaktid ringlevad ja oma keskkonda mõjutavad" ${ }^{82}$ Sellest pöör-

76 Vaata opositsiooni ületamise kohta ka: A. Rigney. Cultural Memory Studies: Mediation, Narrative, and the Aesthetic. - Routledge International Handbook of Memory Studies. Ed. by A. L. Tota, T. Hagen. Routledge, London, 2016, 65-76.

77 K. Jôesalu, R. Nugin. Reproducing Identity Through Remembering: Cultural Texts on the Late Soviet Time. - Folklore: Electronic Journal of Folklore, 2012, 5I, I5-48.

78 K. Jõesalu, E. Kôresaar. Working through mature Socialism.

79 E. Kôresaar, Memory and History.

80 K. Jóesalu. The Meaning of Late Socialism; vt eriti: K. Jóesalu. Dynamics and Tensions of Remembrance.

8I J. Olick. Collective Memory: The Two Cultures. - Sociological Theory, 1999, I7, 3, $333-348$, siin 336; J. Olick. The Politics of Regret: On Collective Memory and Historical Responsibility. Routledge, New York, 2007, 9-II.

82 A. Rigney. The Dynamics of Remembrance, 346. 
dest lähtuvad kultuurimälu uuringud rôhutavad dünaamilisust ehk relatsionaalsust ja protsessipõhisust, intermeedialisust ja performatiivsust, arutledes viiside üle, kuidas mälu ringleb ja suhtleb erinevatel mäletamise väljadel ja nendel tegutsejatega ning mõjutab sotsiaalseid suhteid..$^{83}$ Astrid Erll on rôhutanud kultuurimälu meedialist iseloomu: meedialisust ja vahendamist võib môista kui „,ülitit” mäletamise individuaalse ja kollektiivse mốótme vahel; meediumi - näiteks kirjandusteose - „mälumeediumiks" saamine sóltub selle aktualiseerimisest ja funktsionaliseerimisest ühiskondliku mäletamise protsessis üksikisikute, sotsiaalsete gruppide vôi institutsioonide poolt. ${ }^{84}$ Eluloolise jutustamise môistmine mälumeediumina ${ }^{85}$ interaktsioonis teiste mälumeediumidega, nagu film ja kirjandusteos ${ }^{86}$ ajalookirjutus ${ }^{87}$ vôi ajakirjandus ${ }^{88}$ on vôimaldanud mälu-uuringute interdistsiplinaarses valdkonnas suurenevat dialoogi eri distsipliinide vahel. Üks neist kattuvatest uurimissundadest on mäluaja$\operatorname{lugu}^{89}$ (vôi ka mäludünaamika suund ${ }^{90}$ ), mis tôlgendab mäletamise eri viise, välju ja tegijaid dünaamiliselt seotuna ja muutuvana, ning mis on kujunenud Eesti eluloolistes mälu-uuringutes järk-järgult alates 2000. aastatest. Mäludünaamika lähenemisviis tähendas omaelulooliste minevikunarratiivide seostamist protsessidega, mis toimusid mälutöö institutsionaalsel, seadusandlikul, monumentaalsel ja kultuurilisel mốôtmel. Keskendudes nii performatiivsetele kui ka narratiivsetele aspektidele, on nốukogudejärgset mälukultuuri alates 1989. aastast analüüsitud nii seda kehtestavate kui ka muutust esile kutsuvate sündmuste ja kogemuste eeskätt stalinistlike repressioonide, ${ }^{91}$ sôja- ja paguluskogemuse ${ }^{92}$ ning hilisnôukogude argielu mälestuste kaudu. ${ }^{93}$

Lópuks, kuid mitte vähem olulisena on nôukogudejärgset mäluajalugu analüüsitud ka põlvkondlike identiteetide dünaamika aspektist. ${ }^{94}$ „Pólvkond” ja „pốlvkondlik mälu” on olnud populaarsed

83 Vt kollektiivse mälu uuringute muutumisest lähemalt: M. Tamm. Ajalugu, mälu ja mäluajalugu.

84 A. Erll. Memory in Culture, II3, I24.

85 E. Kõresaar. Life Story as Cultural Memory: Making and Mediating Baltic Socialism Since 1989. - Journal of Baltic Studies, 47, 4, 2016, 2-4.

86 E. Laanes. Trauma keelde tôlgitud.

87 M. Tamm. Ajalugu, mälu ja mäluajalugu, I23-I28.

88 M. Miil. Mäng mäluga: 22. september 1944 Eesti NSV päevalehtedes ajavahemikul 1945-1989. - Ajalooline Ajakiri, 20II, 2 (I36), 189-222.

89 Samas, I25-I28.

90 B. A. Misztal. Theories of Social Remembering. Open University Press, Maidenhead, 2003.

9I T. Anepaio. Reception of the Topic of Repressions in the Estonian Society. - Pro Ethnologia, I4, 2002, 47-65; T. Anepaio. Eesti mäletab!? Repressiooniteema retseptsioon Eesti ühiskonnas. - Mälu kui kultuuritegur, 206-230.

92 R. Hinrikus. How to Remember? The Social Framework of Reinhold Mirk's

Reminiscences of War. - Soldiers of Memory, 297-316; T. Kirss. Rändlindude pesakonnad.

93 K. Jôesalu. Dynamics and Tensions of Remembrance.

94 Mälu- ehk mnemoajaloo mõiste ja kontseptsiooni kohta vt: M. Tamm. History as Cultural Memory: Mnemohistory and the Construction of the Estonian Nation. - Journal of Baltic 
mõisted Eesti 20. sajandi kogemuse tôlgendamise kon tseptualiseerimisel nii mälu-uuringutes kui ka laiemas perspektiivis. ${ }^{95}$ Aastatel 1920-1939 sündinud kohordi, nn vabariigiaegse pólvkonna mälestused on saanud kõige rohkem tähelepanu Baltimaades laiemalt, ${ }^{96}$ kuna Teisel maailmasõjal ja Nóukogude režiimil oli nende elukäigule väga suur mõju. Selle poolvkonna lugusid, mis on Eestis jaotatud väiksemateks gruppideks sôltuvalt inimeste saatusest sõja ajal, on käsitletud spetsiifilistesse mälukogukondadesse kuuluvana. ${ }^{97} \mathrm{Karl}$ Mannheimi arusaam, mis rôhutab avalikus ja poliitilises sfääris toimunud sündmuste osa pólvkondliku mälu kujunemises, ${ }^{98}$ on olnud väga mõjukas, osalt ka 20 . sajandi suursündmuste keskse positsiooni tôttu nôukogudejärgses mälupoliitikas. Uurimistöö on laienenud ka järgmiste pôlvkondade Nóukogude mineviku mõistmisele ja pôlvkondadevahelisele mälutööle, ${ }^{99}$ seades muu hulgas kahtluse alla (elitaarse) pólvkondade konstrueerimise avalike sündmuste kaudu. Mõistet „vaikiv põlvkond” on rakendatud, näitamaks avalike mäludiskursuste vaigistavat mõju generatsioonide konstrueerimisele: sõjajärgse põlvkonna elulookirjutuse näitel on esile toodud, et põlvkonda vôib defineerida ka argikogemuste ja nendest kogemustest jutustamise kaudu. ${ }^{100}$ Pólvkonna mõistet kriitiliselt üle vaadates astusid eluloolised mälu-uuringud traumakesksest mälukäsitlusest sammu edasi.

Studies, 2008, 39, 4, 499-516; Afterlife of Events: Perspectives on Mnemohistory. Ed. by M. Tamm. Palgrave Macmillan, Basingstoke, 2oI5; põlvkondliku mäletamise dünaamika aspekti kohta vt: K. Jóesalu, R. Nugin. Reproducing Identity Through Remembering; K. Jôesalu, E. Kôresaar. Continuity or Discontinuity: On the Dynamics of Remembering "Mature Socialism" in Estonian Post-Soviet Remembrance Culture. - Journal of Baltic Studies, 2013, 44, 2, 177-203; R. Nugin. The 1970s: Portrait of a Generation at the Doorstep. University of Tartu Press, Tartu, 20I5.

95 Ülevaadet põlvkondade kvantitatiivsest ja kvalitatiivsest uurimisest 20. ja 2I. sajandi Eestis vt: Generations in Estonia: Contemporary Perspectives on Turbulent Times. Ed. by R. Nugin, A. Kannike, M. Raudsepp. Tartu University Press, Tartu, 2016.

96 Leedu kohta vt: I. Šutinienè. Eluloo- ja suulise ajaloo uurimine Leedus. - Mäetagused, 2009, 43, I45-I58; Läti kohta vt: B. Bela. Elulood läti ühiskonna uurimise allikana. Mäetagused, 2009, 43, 159-180.

97 T. Kirss. Rändlindude pesakonnad; A. Aarelaid-Tart. Cultural Trauma and Life Stories; E. Kôresaar. Introduction; M. Wulf. Shadowlands: Memory and History in Post-Soviet Estonia. Berghahn, London, New York, 2016.

98 K. Mannheim. Das Problem der Generationen. - Kölner Vierteljahreshefte für Soziologie, I928, 7, 309-330.

99 T. Kirss. Three Generations of Estonian Women; K. Jóesalu, R. Nugin. Reproducing Identity through Remembering; R. Nugin. Negotiating the Past: Some Issues of Transmission of Memories among Estonian Young People. - Studies of Transition States and Societies, 2016, 8, 2, 8I-IOO; R. Nugin. Rejecting, Re-shaping, Rearranging: Ways of Negotiating the Past in Family Narratives. - Memory Studies, 202I, I4, 2, I97-213.

ıоo K. Jóesalu. "We Were Children of Romantic Era". 


\section{„VALGED LAIGUD” ELULOOLISTES M ̈̈LU-UURINGUTES: EESTIVENE NÕUKOGUDEJ ÄRGSED M ̈̈LESTUSED}

Niisiis oli Eesti elulooliste mälu-uuringute trajektoor mälutööst kriitiliste uurimusteni alates 1989. aastast seotud tegelike mäluprotsessidega ühiskonnas. Panustati sümboolsetesse tôe- ja mälestamisprotsessidesse vôi kritiseeriti selle protsessi hegemoonilisi tulemusi, osutades minevikukogemuste erinevustele ja keerukustele. Samas oli mälu-uuringute praktikas ilmne ka kollektiivse „teise” väljajätmise teema, mis kõige enam puudutas eestivenelasi. Püsiv usaldamatus venelaste vastu Eesti avalikus ja ametlikus sfääris, mis on määranud mälupoliitikat Eestis alates taasiseseisvumisest, ${ }^{101}$ on môjutanud nii Eesti mälu-uurijate kontakte vene kogukonnaga kui ka nende valmisolekut eestivene elulugusid uurida.

Vene kogukonna kaasamist elulugude kogumisse kujundasid mitmed filtrid. Keelefilter on kõige silmatorkavam, sest eesti keele valdamine määras inimese osalemise riiklikus mälutöös. Vaid kôige esimene avalik elulookirjutamise üleskutse Eestis 1989. aastal oli suunatud nii eesti- kui ka venekeelsele elanikkonnale. Venekeelseid vastuseid saadeti 1989.-1990. aastal, eestikeelsed aga laekusid ka järgnevatel aastatel. See oli aeg, mil eestikeelne elanikkond mobiliseerus etniliselt ja konsolideerus nôukogudevastasesse iseseisvusliikumisse. Teisalt korraldasid nôukogudemeelsed organisatsioonid, mis toetusid peamiselt venekeelsele elanikkonnale, meeleavaldusi. Kaks eluilma, mida suulise ajaloo uurija Uku Lember on nôukogude kontekstis kirjeldanud kui paralleelseid eluilmu, pôrkusid avalikult. ${ }^{101}$

Kahe kogukonna narratiivsete kogemuste ebakôla, mida vôimendas järgnenud retrospektiivne tóepoliitika, moodustab veel ühe filtri, mille kaudu eestivenelaste mälestuste kogumine ja uurimine on toimunud. Jaago on näidanud, et juba 1989. aastal EKLA-sse saadetud lugudes ilmnes, et eestlased ja venelased omistavad ajaloolisele kogemusele, eeskätt sõjajärgsele perioodile, vastandlikke tähendusi. Eestlaste elulugudes hinnati sõjajärgset perioodi, mil jäädi ilma kodudest ja perekondadest, üldjuhul negatiivselt ning hilisemat nôukogude aega tôlgendati selle taustal; eestivenelased aga hindasid sôjajärgset perioodi positiivselt kui töö ja kodu leidmise aega, millele järgnes hiljem rahulik ja rahuldust pakkuv elu. ${ }^{102}$

IoI U. Lember. Silenced Ethnicity: Russian-Estonian Intermarriages in Soviet Estonia (Oral History). Unpublished PhD Thesis. Central European University, Budapest, 2014.

IO2 T. Jaago. Narrationen von Heimat und Abstammung: Esten und ethnische Minoritäten in Estland erzählen. - Erzählen zwischen den Kulturen. Hrsg. von S. Wienker-Piepho, 
Uue riikliku mälurežiimi kujunemine järgnevatel aastatel lisas veel ühe hierarhilise aspekti eestivenelaste mälestustega tegelemisele. I990. aastatel ei püüdnud mälu ja elulugude uurijad venekeelset elanikkonda hoolmata, tähelepanu fookus oli 2o. sajandi mäletamise probleemidel eestlaste vaatepunktist. Mälu-uurijad ise selgitasid eestivenelaste elulugude puudumist üleriiklikus mälutöös erinevustega eri etniliste gruppide mälupraktikas. ${ }^{103}$ Samas, nagu Irina Paert on sedastanud, „tunnistavad elulookirjutamise kampaaniate korraldajad ja uurijad harva, et venekeelse elanikkonna lugude puudumine vôib olla eestivenelaste elude ja domineeriva mälukultuuri ebakôlade tulemus”. ${ }^{104}$

Lôpuks tuleb venekeelse kogukonna kaasamise puhul arvestada usalduse filtriga. Elulugude kogumise töö eestivenelaste hulgas on seni ühel vôi teisel moel toimunud kriisisituatsioonides, kahe keelepôhise kogukonna vaheliste pingeliste suhete aegadel. ${ }^{105}$ Pärast I990. aastate pausi tehti uusi katseid venekeele vähemuse mälestusi koguda 20oo. aastail, mil Teise maailmasôja mäletamise teema aktualiseerus niinimetatud monumentide sõja ja pronkssôduri kriisi tôttu. Mälestuste kogumine ei ônnestunud siiski mitte venekeelses meedias välja kuulutatud avaliku elulookirjutamise üleskutse abil, vaid väike hulk lugusid saadi 2007 . aastal tänu sellele pühendunud venekeelsete inimeste pingutuste tulemusena. ${ }^{106}$ Usalduse ja rahvusliku identifitseerimise küsimus kerkis üles ka intervjuupóhistes uurimisprojektides. ${ }^{107}$ Jaago osutab siinkohal, et ebakindel olukord, milles eestivene mälestuste kogumine on toimunud, peegeldub ka jutustajate teemavalikus. 1989.-I990. aastal keskendusid eestivenelased tavaliselt oma seostele Eestiga, kuid pärast pronkssôduri kriisi rääkisid jutustajad peamiselt erasfäärist (perekonnast, kodust ja pereajaloost), kuigi nende elukäigu raamistik oleks võimaldanud analüüsida oma kogemusi ka ajaloolis-poliitilises vôtmes. Siiski eelistas enamik jutustajaid potentsiaalselt konfliktsetest teemadest vaikida. ${ }^{108}$

K. Roth. Waxmann, Münster, New York, München, Berlin, 2004, I73-185, vt ka A. Aarelaid-Tart. Cultural Trauma and Life Stories.

I03 T. Jaago. Nôukogudeaegne migratsioon ja selle ilmnemine omaelulugudes. - Acta Historica Tallinnensia, 20II, I7, I, I40-I49; K. Jóesalu, E. Kôresaar. Continuity or Discontinuity, 196.

IO4 I. Paert. Memory of Socialism and the Russian Orthodox Believers in Estonia. - Journal of Baltic Studies, 2016, 47, 4, 497-512, siin 500.

Ios T. Jaago. Nóukogudeaegne migratsioon ja selle ilmnemine elulugudes.

Io6 Vt Эстония - мой дом: Жизнеописания эстоноземельцев. Сост. В. Паклар. Tänapäev, Tallinn, 2009. Erinevatel andmetel on EKLA-s kokku umbes sadakond venekeelset lugu. Eestivenelased on mälestusi kirjutanud ka eesti keeles.

IO7 Näiteks Tallinna Ülikooli kultuuriuurijate kogemus venelastega elulooliste intervjuude tegemisel 200I-2005 näitas, et ei piisanud venekeelsest keskkonnast pärit intervjueerijast, vaid ka esimesed kontaktid kogukonnaga pidid sôlmima „lojaalselt meelestatud humanitaarharitlased”. А. Аарелайд-Тарт, А. Хачатурян. Дискурс культурной травмы в русскоязычной среде Эстонии. - Социологические исследования, 2006, го, 57-65.

Iо8 Vt Эстония - мой дом; T. Jaago. Nôukogudeaegne migratsioon ja selle ilmnemine elulugudes, I43, ja konfliktidest vaikimisest samas I45. 
2007. aastast alates on suuremate riiklike arhiividega seotud elulugude kogujad keskendunud eestivenelaste olemasolevate elulugude avaldamisele, mitte nende kaasamisele jätkuvasse mälutöösse. ${ }^{109}$ Eestivenelaste endi autobiograafilised algatused olid suunatud kultuuriliselt ühendava identiteedi otsingutele. Enamik neist mäluinitsiatiividest on keskendunud perioodile enne 194I. aastat ega hõlma - väheste eranditega Nôukogude minevikku. ${ }^{110}$

Nagu Paert on osutanud, tuleks uurimusi, sealhulgas eestivene narratiivse mäletamise uuringuid näha laiemas vene vähemusse suhtumise ajaloolises trendis endistes Nôukogude vabariikides. ${ }^{111}$ See uurimissuund on keskendunud Nôukogude impeeriumi kui vene vähemuse sotsiaalse ja kultuurilise identiteedi aluse kokkuvarisemisest pôhjustatud traumale. Selle järgi ei määratle eestivenelaste spetsiifilist seisundit niivôrd keel ja ühine kultuur, kuivôrd endise privilegeeritud positsiooni kaotuse tunnetus. ${ }^{112}$ Viimasel ajal on mälu-uurijad pööranud tähelepanu ka teistele identifitseerumisvõimalustele, nagu näiteks vene ôigeusk kui kultuuriressurss mälupraktikates, mis eristab „eestivenelase” kuvandit. ${ }^{113}$ Lemberi süvaintervjuud eestivene segaperedes tõid esile sotsiaalse välja, millel kultuurikommunikatsioon pidi leidma väljundi vaatamata ideoloogilisele survele ja millel mõisteid „eestlane” ja „venelane” väljendati pigem elude ja enesemääratlemise värvika mustri kui millegi homogeense kaudu. $^{114}$

I09 Pronkssôduri konfliktile järgnenud kollektiivse šoki olukorras loodi eraalgatus Mäluvara, mis 20IO-20II kogus eestivenelastelt mälestusi nende Eestisse asumisest aastatele 1940-1990 - Mäluvara [koduleht]. http://maluvara.edicypages.com (07.07.2020). Seni on see osutunud kôige ulatuslikumaks eraviisiliseks suulise mälu kogumise algatuseks Eestis, mille tulemusena koguti üle ı2o eri pikkusega loo kas kirjalikult vôi intervjuu või elektroonilise küsimustiku vahendusel. Kampaania algataja nägi selles leppimise ja mõistmise aktsiooni, mille eesmärk oli aidata isiklike lugude kaudu môista venelastest kaasmaalasi kui indiviide, mitte häbimärgistada neid „kollektiivse teisena” (Meie eluteed Eestis. Toim. M. Lepikult. Avaldamata käsikiri autorite valduses).

IIo Vt nt Tartu Ülikooli eestivene uurijate digiprojekti Esto-Russica, mis on pühendatud Eesti vene kogukonna elule ja kultuurile: http://estorussica.ut.ee/ (07.07.2020). Vt I. Paert. Religion and Generation: Exploring Conversion and Religious Tradition Through Autobiographical Interviews with the Russian Orthodox Believers in Estonia. Generations in Estonia, I88-2I4.

III I. Paert. Memory of Socialism.

II2 А. Аарелайд-Тарт, А. Хачатурян. Дискурс культурной травмы в русскоязычной среде Эстонии.

II3 I. Paert. Religion and Generation

II4 U. Lember. Inter-generational Transmission of Pasts in Late Soviet Estonia: Oral History Perspective in Inter-Marriage Setting. - Generations in Estonia, I59-I87. 


\section{KOKKUVÕTE}

Artikkel keskendus mälu-uuringute ja eluloouuringute suhetele nôukogudejärgsete mäluprotsesside ja mälestuste uurimisel. Eluloolised mälu-uuringud Eestis kasvasid välja kommunismivastasest mälutööst I980. aastate lópul ja I990. aastate algul ning olid 1990. ja 2000. aastatel osa sümboolsest tôe- ja mälestamisprotsessist. Need vormisid aktiivselt minevikutôlgendusi, kollektiivseid „mälunihkeid” nii esile kutsudes kui ka neid aeglustades. 1990. aastail oli elulugude kogumine seotud Eesti ühiskonna kultuurilise taastamismeelsusega, mis väärtustas kultuurilist, eluloolist ja (etnilist) rahvusühtsust. 1990. ja 2000. aastail keskendus see 2o. sajandi traumaatilistele kogemustele. Seega panustasid Eesti eluloolised mälu-uuringud oma varases etapis uue nóukogudejärgse mälurežiimi kujunemisse, kattes ainult osa nôukogude perioodi kogemuste spektrist ja jättes rahvuslikku traumalugu kahtluse alla seadvad mälestused pigem kôrvale.

Nôukogudejärgset eluloolist ja kultuurimälu puudutavad uurimused hakkasid alates 1990. aastate lópust kriitiliselt mõtestama postkommunistliku mälutöö hegemoonilisi tagajärgi. Uurimistöös kontseptualiseeriti nôukogudejärgseid mäluprotsesse dünaamilistena ja sôltuvana erinevatest kontekstidest, vastuolulistest kogemustest ja vôimustruktuuridest. Metodoloogiliselt arenesid Eesti eluloolised mäluuuringud Saksa kultuurimälu koolkonna (Assmannid) ja Angloameerika sotsiaalse mälu koolkonna ristumiskohas. Algset sisuanalüütilist lähenemist narratiivsele mälule täiendasid performatiivsed, protsessuaalsed ja ajakomplekssed meetodid, mis osutasid kultuuridünaamika kasvavale tähtsusele mälu-uuringutes. Vahendamist ja meedialisust rôhutava nn uue kultuurimälu uuringute mójul on elulugusid ja mälestusi hakatud mõistma ühe mälumeediumina teiste hulgas, mis on ergutanud dialoogi eri distsipliinide ja mälu-uuringu perspektiivide vahel.

Eesti Nôukogude mineviku tôlgendamist käsitlevad uurimused on näidanud, et tegelikus mälutöös on kultuuriline ja kommunikatiivne seotud, põimunud ja teineteisele tuginev. Küüditamislugude uurimise tulemusena on hiljutiste dekoloniseerimiskatsete valguses kahtluse alla seatud traumateooria üldhõlmavus. Tegeledes kriitiliselt uute põlvkondlike mäludega postkommunistliku mäletamise maastikul ja môtestades ümber pôlvkonna mõistet, on eluloolised mälu-uuringud astunud traumakesksest mälukäsitlusest sammu edasi.

Eesti elulooliste mälu-uuringute analüüs - nii mälutöö kui ka kriitilise uurimise vormis - on näidanud selle väga tihedat seotust tegelike 
mäluprotsessidega ühiskonnas. See ilmneb mitte üksnes teemavalikus, vaid ka mäluteooriate ja kriitika arengus. Samuti on senise eluloouurimise suurim lünk - eestivenelaste nôukogudejärgsete mälestuste kogumine ja uurimine - seotud Eesti avalikus ja ametlikus sfärris jätkuva usaldamatusega venekeelse kogukonna suhtes. Alles viimasel ajal on tehtud uurimusi, mis osutavad eestivene eluilmade ja mälestuste keerukale olemusele.

Siinne artikkel pakkus ühe, eluloouuringutele keskendunud sissevaate 1990.-2000. aastatel Eesti akadeemilisel maastikul kanda kinnitanud mälu-uurimisse. Praeguste mälu-uuringute mitmekesine väli on aga kujunenud mitme distsiplinaarse muutuse tulemusena. Viimase umbes kümne aasta jooksul on need distsiplinaarsed vaatepunktid lähenenud, dialoogibaas suurenenud ning vôimaldanud ühiskondlikke ja kultuurilisi mäletamisprotsesse analüüsida interdistsiplinaarselt ja teineteist täiendavalt. Seega on tulevikus võimalik ka valdkondadeülese ja põimitud mälu-uuringute perspektiivi läbikirjutamine.

\section{Tänuavaldus}

Täname ajakirja peatoimetajat ja anonüümseid retsensente pôhjaliku tagasiside eest. Uurimistööd toetas Eesti Teadusagentuuri grant PRGIo97.

FROM MEMORY WORK TO

BIOGRAPHICAL MEMORY RESEARCH:

NOTES ON THE INTERCONNECTIONS

BETWEEN BIOGRAPHICAL RESEARCH

AND MEMORY STUDIES SINCE THE POST-COMMUNIST TURN

Ene Kôresaar, Kirsti Jóesalu

This article provides an analysis of the intersection of memory studies and biographical research in the study of Estonian post-Soviet memory processes and memories. Both lines of research emerged during the postcommunist turn, albeit with different dynamics and different possibilities to build on existing research traditions. Both are multidisciplinary in nature. This article focuses on the points of contact between biographical research and memory studies in social and scientific methodological processes. The authors show that biographical research, which played 
a significant role in documenting and disclosing the long-silenced past throughout Eastern Europe during the collapse of communist regimes, has shifted from memory activism to critical examination of memory contexts, mnemonic actors, power relations, and contradictions. To this end, first, the impact of the cultural institutions dealing with collecting oral histories and life stories is analysed as contributors to the Estonian post-communist turn. Second, an overview is provided of post-communist biographical research in Estonia from a memory studies perspective, focusing both on influential theories and methods and pointing to con tributions to international memory debates. In addition, gaps in biographical memory work and research are highlighted.

Biographical memory studies in Estonia grew out of anticommunist memory work in the late 1980 os and early I990s, being part of a symbolic process of truth and remembrance, actively shaping interpretations of the past, evoking and slowing down collective 'memory shifts'.

In the 1990s, the collection of life stories was related to the sense of cultural restoration in Estonian society, which valued cultural, biographical, and (ethnic) national unity. In the I99os and 2000 , it focused on the traumatic experiences of the twentieth century. Thus, in its early stages, Estonian biographical memory research contributed to the formation of a new post-communist memory regime, which covered only a part of the spectrum of Soviet-era experiences and rather left aside the memories that differed from the national trauma story.

Research from the late i99os onwards became critical of the hegemonic consequences of post-communist memory work. Post-Soviet memory processes were conceptualised as dynamic and dependent on different contexts, conflicting experiences, and power structures. Methodologically, Estonian biographical memory research developed at the intersection of the German School of Cultural Memory and the Anglo-American School of Social Memory. The initially content-based approach to narrative memory was complemented by performative, procedural, and time-complex approaches that indicated the growing importance of cultural dynamics and mediation in memory research. As a result of the so-called new cultural memory studies, which emphasizes mediation and media, life stories and memories have come to be understood as a medium of memory, among others, which has stimulated dialogue between different disciplines and perspectives on memory studies paving way to a more dialogic, interdisciplinary and complementary approach to social and cultural memory. 
Research on the interpretation of the Estonian Soviet past has shown that in memory work, cultural and communicative remembering are interconnected, intertwined, and based on each other. Examination of deportation stories has called into question the universality of trauma theory in the light of its recent attempts at decolonisation. By critically addressing new generational memories in the landscape of postcommunist remembrance and rethinking the concept of generation, biographical memory research has taken a step beyond a trauma-centred approach to memory.

The analysis of Estonian biographical memory research - both in the form of memory work and critical research - showed its very close connection with the memory processes in society both in terms of the choice of topics and the development of memory theories and criticism. In addition, the biggest gap in Estonian memory research so far - collecting and researching the memories of Estonian Russians - is related to the continuing distrust of the Russian-speaking community in the Estonian public and official spheres. It is only recently that research has been conducted that points to the complex nature of Estonian Russian lifeworlds and memories. 